\title{
Persepsi Konsumen Terhadap Endorser dan Citra Produk (Studi Kasus Sabun Lux)
}

\author{
Nurina Orta Darmawati, Putri Dwitasari dan Luri Renaningtyas \\ Departemen Desain Produk Industri, Fakultas Teknik Sipil dan Perencanaan, \\ Institut Teknologi Sepuluh Nopember (ITS) \\ email: nurinaorta@gmail.com
}

\begin{abstract}
Abstrak. Sebuah iklan merupakan bentuk budaya populer yang turut mengkonstruksi budaya di masyarakat. Sebagai sebuah media komunikasi audio visual yang berfungsi menyampaikan pesan kepada calon konsumen, iklan harus memiliki strategi kreatif dalam menghadapi persaingan dengan produk sejenis. Salah satu strateginya menggunakan selebriti. Iklan sabun Lux memiliki potensi yang dapat diangkat menjadi topik penelitian meliputi masalah sosial, budaya, perempuan dan gaya hidup. Oleh karena itu diteliti persepsi konsumen terhadap penggunaan selebriti perempuan sebagai endorser yang menjadi inti iklan dan sejauh mana efek dari strategi iklan ini mempengaruhi kaum perempuan akan pandangan mereka terhadap kecantikan. Metode yang digunakan adalah metode kualitatif dan kuantitatif. Penelitian ini diharapkan dapat memperluas pengetahuan mengenai iklan, endorser serta kaitannya dengan mitos antropologi dan kecantikan masa kini. Bagi perempuan, diharapkan penelitian ini juga memberi pandangan lebih luas lagi dalam memaknai kecantikan. Endorser Lux memiliki kualitas daya tarik yang baik, terbukti dari daya tarik endorser Lux yang dipersepsi oleh konsumen dengan baik, namun untuk membuat sebuah strategi endorser yang sukses, unsur lain seperti kredibilitas dan relevansi juga harus diperhatikan pengiklan.
\end{abstract}

Kata Kunci: persepsi konsumen, iklan, endorser, merek, kecantikan.

Abstract. An advertisement is a form of popular culture in the society, that constructs the culture in the community. Advertisement as a media of audio visual comunication that serves to convey the message to prospective customers must have a creative to compete with similar products. One of which is the use of celebrities. Lux soap ads are potential to be observed because there are many problems that can be promoted to research topics include social, cultural, women and lifestyle. Therefore, this study assess the perceptions of women towards celebrity endorser who became the core of advertising and how far this strategy affects women and their view of beauty. The method is qualitative and quantitative. The benefit of the research are to expand knowledge about advertising, endorser and its relation to myth and beauty of contemporary anthropology. For women, it is expected to gives a broader view on the meaning of beauty. Lux is an example of endorsment who has strength mainly in the quality of physical attractiveness, based on the consumer perception, however to make a succesful endorser campaign strategy, the other two elements such as credibility and relevance must also be considered by the advertisers.

Keywords: consummer perception, advertisment, endorser, brand, beauty

\section{PENDAHULUAN}

Iklan merupakan salah satu media komunikasi dalam penyampaian pesan khususnya pesan yang bersifat komersial. Iklan dapat menyampaikan informasi mengenai produk baik berupa barang maupun jasa yang mereka tawarkan kepada para konsumen. Penyusunan iklan tidak terlepas dari segmentasi pasar mana yang akan disasar, produk yang ditawarkan dan bagaimana kondisi persaingan pasar saat ini, termasuk media apa saja yang akan dipergunakan dalam menyampaikan pesan-pesan komersil tersebut. Sebuah iklan harus dapat memberikan atau dapat mengubah suatu citra (image) terhadap produk yang diiklankannya sehingga konsumen dapat menilai dan mempunyai suatu persepsi terhadap produk tersebut.

Iklan merupakan sebuah perangkat yang ampuh untuk menciptakan 'need', 'want' and 'buy' [1]. Iklan tv yang menyampaikan pesan verbal visual dari produsen kepada calon konsumen harus memiliki strategi kreatif dalam menghadapi persaingan dengan produk sejenis. Hal ini menyebabkan adanya persaingan dalam merebut perhatian khalayak untuk iklan-iklannya. Dewasa ini sebuah produk diiklankan dengan berbagai cara, di antaranya mengaitkan dengan isu-isu sosial terkini, dan fungsi iklan sekarang bukan hanya sekedar memberi informasi semata [2]. Periklanan harus dibuat semenarik mungkin agar dapat menarik minat masyarakat, orisinal, serta memiliki ciri khas dan persuasif sehingga para konsumen secara suka rela terdorong untuk melakukan tindakan yang diinginkan pengiklan.

Saat ini dalam berbagai iklan, penggunaan selebriti sebagai salah satu strategi pemasaran, dinilai efektif untuk membentuk stopping power bagi audiens. Kehadiran selebriti dimaksudkan untuk mengkomunikasikan suatu merk produk dan membentuk identitas serta menentukan citra produk yang diiklankan. Pemakaian selebriti sebagai daya tarik iklan (advertising appeals), dinilai dapat mempengaruhi preferensi konsumen karena selebriti menjadi reference group yang mempengaruhi perilaku 
konsumen. Bagi produk baru, penggunaan endorser atau pembicara merupakan upaya pengiklan untuk meraih publisitas dan perhatian (attention getting power) produk tersebut. Meskipun mereka adalah aktor, selebriti, eksekutif, atau kepribadian yang diciptakan, endorser terbaik adalah mereka yang bisa membangun citra merek yang kuat [3].

Popularitas selebriti memang tidak dapat dipungkiri menjadi suatu fenomena tersendiri karena menjadi salah satu fokus publisitas di berbagai media cetak dan media elektronik, dan bahkan kehidupan pribadinya sangat ditunggu pers sebagai headline berita. Keberhasilan dalam membangun brand image ini sangat ditentukan oleh persepsi konsumen terhadap selebriti yang menjadi ikon produk tersebut. Ketika seorang celebrity endorser dipersepsi secara positif oleh masyarakat, diharapkan positif pula brand image yang terbentuk di benak konsumen. Namun demikian, tidak menutup kemungkinan munculnya brand image dalam pikiran konsumen yang tidak relevan dengan persepsinya terhadap celebrity endorser.

Berdasarkan fenomena di atas maka digunakanlah iklan produk sabun Lux sebagai studi kasus. Iklan Lux tidak sebatas sebagai alat promosi saja, namun merupakan sebuah bauran komunikasi dari pihak produsen kepada konsumennya, karena pada iklan Lux, banyak permasalahan yang dapat diangkat menjadi topik penelitian yang misalnya masalah sosial budaya, serta perempuan dan gaya hidup.

Penelitian ini mendeskripsikan sejauh mana persepsi konsumen yaitu kesan dan pengalamannya terhadap produk mempengaruhi identitas produk tersebut dengan memetakan bagaimana persepsi konsumen sabun Lux terhadap endorser produk Lux. Lebih jauh lagi melalui focus group discussion yang dianalisis dengan teori budaya kecantikan, perempuan dan media, serta stereotip perempuan, deskripsi persepsi konsumen tersebut pada akhirnya mencerminkan nilai-nilai kecantikan yang ada di masyarakat Indonesia saat ini.

\section{METODE PENELITIAN}

Penelitian menggunakan metode kuantitatif dan deskriptif kualitatif, yaitu mendeskripsikan fakta tertentu secara aktual dan cermat. Metode pengumpulan data kuantitatif dilakukan dengan membagikan kuesioner kemudian dilakukan analisis isi untuk tahap pertama, yakni untuk menjawab masalah persepsi konsumen mengenai citra endorser. Pada bagian ini, digunakan parameter kriteria endorser yang berasal dari pihak sabun Lux yakni cantik secara fisik, merawat kecantikan, merawat diri, seorang pemain film, memiliki citra diri yang baik dan berpenampilan menarik. Setelah mengetahui persepsi konsumen mengenai citra endorser maka untuk meyakinkan hasil dari temuan yang didapat dari analisis isi diatas, juga akan dilakukan focus group discussion di mana pertanyaan-pertanyaan yang muncul di dalamnya meliputi hal-hal seputar citra endorser dan citra produk. Kemudian akan dilakukan pembahasan tahap kedua yakni menganalisis nilai-nilai kecantikan yang dihasilkan dari citra endorser dan citra produk dengan bantuan kajian budaya dan perempuan [4].
Sehingga secara keseluruhan mampu menjawab pertanyaan kedua yaitu sejauh mana persepsi konsumen terhadap Lux mempengaruhi identitas produk tersebut. Untuk menyimpulkan semuanya sekaligus menjawab pertanyaan ketiga deskripsi persepsi konsumen terhadap endorser maupun produk Lux dianalisis dengan teori budaya kecantikan, perempuan dan media, serta stereotip perempuan yang merujuk pada cerminan nilai-nilai kecantikan yang ada di masyarakat Indonesia saat ini.

Berikut merupakan sistematika jalannya metode focus group discussion:

FGD diikuti oleh 10 orang perempuan yang berusia antara 20 hingga 30 tahun, dengan alasan pada rentang usia ini, seseorang masih belum memiliki pilihan tetap, dan terbuka pada perubahan dan modernisasi. Pendidikan minimal minimum Sarjana S1, dengan asumsi bahwa mereka digolongkan berpendidikan. Pertanyaan dalam FGD meliputi endorser, iklan dan produk Lux.

\section{HASIL DAN PEMBAHASAN}

Berdasarkan tabel kesimpulan mengenai persepsi konsumen terhadap endorser sabun Lux, maka penjelasan pada masing-masing kriteria adalah sebagai berikut:

\section{a. Kredibilitas}

Kriteria kredibilitas endorser mempunyai unsur-unsur seperti pengalaman, keterampilan, kejujuran, integritas dan ketidakberpihakan dari seorang endorser. Dalam hal ini, responden menilai unsur kredibilitas endorser Lux dari kepintaran seorang endorser, popularitas, prestasi, kepandaian merepresentasikan diri di hadapan publik, kepandaiannya bicara dan berdandan, serta kelakuannya yang baik di mata publik. Dari banyaknya kriteria kredibilitas yang disebutkan, jelas kredibilitas endorser telah dipersepsi dengan baik oleh konsumen. Kredibilitas tertinggi diperoleh Dian Sastro dengan 44 kotak, sedangkan Atiqah di tempat selanjutnya dengan 34 kotak. Kredibilitas endorser terkecil dimiliki oleh Luna Maya dengan 23 kotak.

Secara garis besar, konsumen menilai bahwa endorser Lux pintar, diwakili dari dua endorser Lux yaitu Dian Sastro dan Atiqah Hasiholan. Endorser yang tidak mendapat penilaian smart dari responden adalah Mariana Renata, dan hal ini dikarenakan minimnya pengetahuan responden akan kehidupan pribadi si endorser. Dian Sastro dan Atiqah, di lain pihak banyak mendapat ekspos media mengenai kehidupan pribadi, dan Atiqah walaupun masuk kategori endorser paling baru di antara semuanya, memiliki ekspos yang baik akibat usaha pihak Lux memperkenalkan dirinya kepada publik, sehingga persepsi konsumen yang lebih baik dapat dibentuk. Tamara Blezynski dan Luna Maya juga masuk kategori pintar (smart), dipersepsi memiliki kriteria tersebut. 
Tabel 1. Tabel kesimpulan persepsi konsumen tehadap endorser sabun Lux

\begin{tabular}{|c|c|c|c|c|c|c|}
\hline \multicolumn{2}{|c|}{ Parameter Kecantikan } & \multicolumn{5}{|c|}{ Responden (Anggota FGD) } \\
\hline $\begin{array}{c}\text { Teori } \\
\text { Endorser }\end{array}$ & $\begin{array}{c}\begin{array}{c}\text { Pihak } \\
\text { Konsumen }\end{array} \\
\end{array}$ & Luna Maya & Dian Sastro & $\begin{array}{c}\text { Tamara } \\
\text { Blexynski }\end{array}$ & $\begin{array}{c}\text { Mariana } \\
\text { Renata }\end{array}$ & $\begin{array}{c}\text { Atiqah } \\
\text { Hasiholan }\end{array}$ \\
\hline \multirow{7}{*}{ Kredibilitas } & $\begin{array}{c}\text { Smart } \\
\text { (Pintar) }\end{array}$ & 5 & 8 & 2 & & 5 \\
\hline & Artis Terkenal & 5 & 6 & 7 & 7 & 4 \\
\hline & Artis beprestasi & & 6 & 3 & & 7 \\
\hline & Pintar berdandan & 5 & 4 & 5 & 7 & 2 \\
\hline & Pandai Bicara & 3 & 7 & 6 & & 5 \\
\hline & $\begin{array}{c}\text { Pandai Membawa } \\
\text { Diri }\end{array}$ & 4 & 7 & 6 & 7 & 3 \\
\hline & Kelakuan baik & 1 & 6 & 2 & 6 & 8 \\
\hline \multicolumn{2}{|c|}{ jumlah } & 23 & 44 & 31 & 27 & 34 \\
\hline \multirow{9}{*}{$\begin{array}{c}\text { Daya Tarik } \\
\text { Fisik }\end{array}$} & $\begin{array}{c}\text { Tubuh dan Kulit } \\
\text { Terawat }\end{array}$ & 4 & 3 & 7 & 7 & 4 \\
\hline & Seksi & 3 & & 6 & & 8 \\
\hline & Tmggi & 7 & 8 & 5 & 6 & 5 \\
\hline & Tubuh langsing & 8 & 8 & 7 & 6 & 8 \\
\hline & Kullt Puth & 8 & 4 & 9 & 6 & 5 \\
\hline & Wajgh Melayu & & 5 & & & 5 \\
\hline & Wajeh Kaukasian & 5 & & 7 & 6 & \\
\hline & Rambut Lurus & 2 & 2 & & 1 & \\
\hline & Rambut panjang & 3 & & 6 & & 5 \\
\hline \multicolumn{2}{|c|}{ jumlah } & 40 & 30 & 42 & 32 & 40 \\
\hline \multirow{2}{*}{ Kecocokan } & $\begin{array}{c}\text { Karahter } \\
\text { Unik }\end{array}$ & 3 & 6 & 2 & 8 & 8 \\
\hline & Matang (Devasa) & 3 & 6 & 8 & 2 & 9 \\
\hline \multicolumn{2}{|c|}{ jumlah } & 6 & 12 & 10 & 10 & 17 \\
\hline
\end{tabular}

Unsur artis terkenal dipersepsi dengan baik oleh seluruh responden, di mana tingkat popularitas endorser sangat tinggi, dimiliki oleh Tamara, Mariana Renata dan Dian. Unsur keterkenalan endorser yang paling rendah dimiliki oleh Atiqah, di mana hal ini dikarenakan kurangnya ekspos media dan frekuensi penampilannya yang dinilai paling minim oleh responden. Unsur Artis berprestasi paling baik dipersepsi oleh konsumen pada Dian Sastro dan Atiqah Hasiholan, karena prestasi mereka di berbagai penghargaan perfilm-an Indonesia. Luna Maya, dan Mariana Renata dinilai paling rendah oleh responden, karena sepengetahuan mereka kekuatan kedua endorser bukan terletak pada poin prestasi.

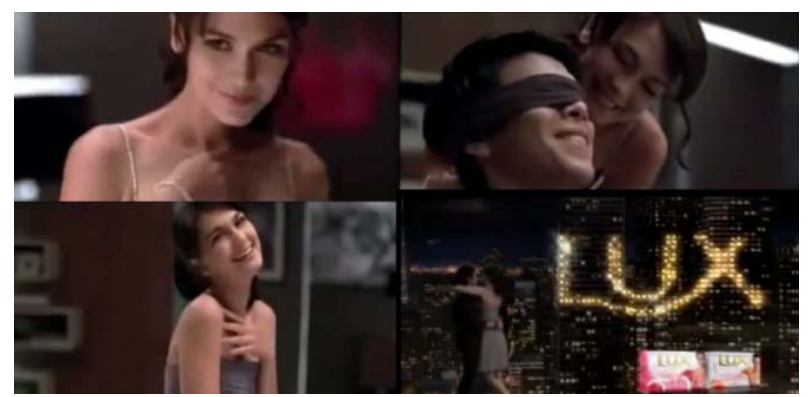

(Sumber: https://www.youtube.com/watch?v=BQJSaA6yDVc) Gambar 1. Iklan sabun Lux Couple Edition dengan Luna Maya sebagai endorser

Unsur pintar berdandan dimiliki oleh keseluruhan endorser Lux, dengan nilai tertinggi pada Mariana, namun yang paling kecil dimiliki oleh Atiqah Hasiholan, dan hal ini dikarenakan penampilan Atiqah yang dinilai paling sedikit frekuensinya di antara keempat endorser lain. Unsur selanjutnya adalah pintar berbicara, yang dimiliki paling banyak oleh Dian Sastro. Dian dipersepsi paling baik karena responden menyukai gaya berbicara endorser tersebut, dinilai paling meninggalkan kesan dari pada keempat endorser yang lainnya. Mariana tidak mendapat kesan pandai bicara, karena penampilannya yang minim untuk kehidupan pribadi di media massa.

Kriteria pandai membawa diri dipersepsi dengan baik oleh konsumen terhadap kelima endorser, namun yang paling sedikit dimilliki oleh Atiqah Hasiholan dikarenakan penampilan yang paling sedikit diantara keempat endorser lainnya, sedangkan yang tertinggi ada pada Dian Sastro dan Mariana Renata. Unsur kelakuan baik dipersepsi oleh konsumen dari pemberitaan media tentang para endorser Lux di atas, dan keseluruhan endorser memiliki pemberitaan yang dinilai sangat positif oleh responden. Seorang endorser dinilai memiliki unsur kelakuan baik yang paling sedikit yaitu Luna Maya, namun bagi responden berita tersebut hanya sedikit saja berpengaruh bagi unsur kredibilitas Luna Maya yang lain.

\section{b. Daya Tarik}

Para selebriti dapat menjadi kekuatan yang digunakan oleh pengiklan sebagai daya tarik produk. Oleh karena itu pemilihan endorser yang cocok sangatlah penting untuk menyampaikan pesan tertentu kepada target audience, untuk selanjutnya pesan tersebut dipersepsi sendiri oleh para konsumen yang dituju tadi. Tentunya persepsi yang kemudian dibentuk haruslah positif, karena tindakan individu selanjutnya dipengaruhi murni oleh persepsi mereka sendiri, bukanlah realitas yang obyektif sesungguhnya. Persepsi positif tadi dibantu dengan hadirnya para endorser yang memberi kesan baik tentunya.

Daya tarik meliputi keramahan, menyenangkan, fisik, pekerjaan sebagai dimensi dari konsep daya tarik [5]. Daya tarik meliputi selain kecantikan fisik juga beberapa unsur lain seperti gaya hidup, kepribadian, keatletisan tubuh dan lainnya. Dari tabel analisa isi diatas, terlihat bahwa unsur daya tarik atau attractiveness merupakan unsur tertinggi yang dipersepsi oleh konsumen, dan penampilan endorser dengan daya tarik dapat sangat mempengaruhi persepsi konsumen akan produk. Banyaknya unsur daya tarik yang ada pada endorser sabun Lux juga berarti bahwa semakin sesuai pesan iklan yang ingin disampaikan dan endorser yang membawakan.

Unsur seperti tubuh dan kulit yang terawat, tubuh tinggi, langsing dan kulit putih dimiliki oleh kesemuanya endorser sabun Lux. Yang menjadi perhatian adalah Lux mempunyai kekhasan dalam memilih endorser, yaitu endorser mewakili dua tipe ras yang berbeda, yaitu mewakili kecantikan asia dan kecantikan eropa. Fitur wajah tersebut dipersepsi dengan baik oleh konsumen, dan diterima sebagai salah stu kekuatan endorser Lux. 


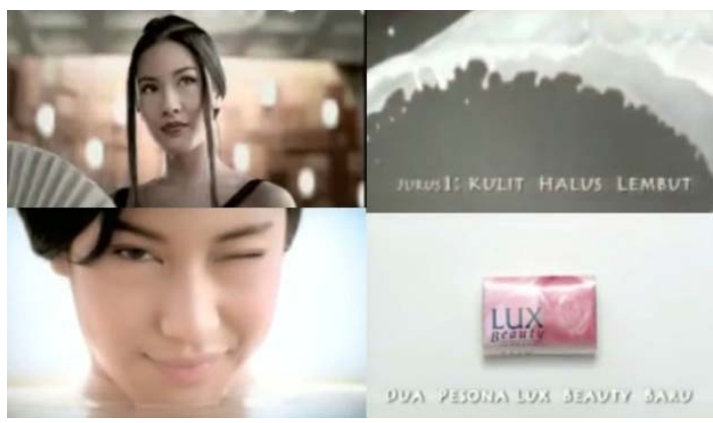

(Sumber: https://www.youtube.com/watch?v=tBWGW2lE9BE) Gambar 5. Iklan Lux dengan Dian Sastro sebagai endorser

Unsur tubuh dan kulit yang terawat dimilki paling tinggi oleh Tamara Blezynski dan Mariana, disusul oleh Luna dan Atiqah, di mana Dian mendapat nilai paling kecil. Tubuh seksi dimiliki oleh Atiqah, Tamara, dan Luna, sedangkan Dian dan Mariana tidak dipersepsi sebagai endorser yang seksi. Tubuh tinggi dinilai responden paling tinggi dimiliki oleh Luna, Mariana, Tamara dan Atiqah, sedangkan Dian tidak dinilai memiliki tubuh tinggi oleh responden. Tubuh langsing dinilai dimiliki oleh keseluruhan endorser, dan memiliki nilai yang kurang lebih sepadan pada kelima endorser tersebut. Kulit putih dipersepsi paling tinggi pada Tamara, Luna dan Mariana, di mana ketiganya memang endorser dengan etnis campuran kaukasian, sedangkan Dian dan Atiqah juga dipersepsi sebagai endorser dengan kulit putih, hanya saja nilainya lebih rendah.

Secara keseluruhan daya tarik fisik paling besar dimiliki oleh Tamara, Luna maya dan Atiqah. Sedangkan daya tarik fisik yang paling kecil dipersepsi konsumen pada Dian Sastro. Unsur daya tarik fisik merupakan unsur yang dipersepsi oleh responden paling banyak, sehingga dapat dilihat bahwa unsur tersebut merupakan unsur dari endorser yang paling banyak dipersepsi dan dinilai oleh responden.

\section{c. Kecocokan}

Hasil analisa tabel di atas dinilai cocok dengan kriteria dari Shimp, karena konsumen cenderung lebih menyukai endorser dengan kemiripan karakteristik dengan dirinya. Seorang selebriti dituntut untuk memiliki kriteria kecocokan (relevansi) dengan produk atau citra yang ingin dibentuk oleh produsen. Selebriti tersebut dituntut untuk memiliki kesamaan karakter dengan konsumen dalam hal umur, gender, etnis dan kelas sosialnya. Hal tersebut yang mendasari pemilihan bintang Lux dan strategi pengiklanan yang membuat endorser sedekat mungkin dengan konsumennya

Dari hasil analisa focus group di atas, endorser Lux memiliki kelebihan di bidang keunikan fisik yang membuat responden merasa familiar dengan etnis dan karakter kedewasaan endorser. Etnis yang paling diwakili yaitu oleh Dian Sastro dan Atiqah, di mana responden melihat kecantikan endorser yang sangat Indonesia, sedangkan ketiga endorser lainnya walaupun memiliki karakter etnis yang non-Indonesia, tapi karena memiliki nama dan keturunan lokal, maka responden merasa bisa menerima dualitas etnis endorser tadi, dan menganggapnya sebagai nilai lebih.
Dalam periklanan, sebuah perusahaan harus mempertimbangkan pangsa pasar dan basis konsumen [6]. Merek yang berpangsa pasar tinggi biasanya membutuhkan pengeluaran iklan yang lebih sedikit guna mempertahankan pangsa pasarnya. Para pengiklan dan biro-biro periklanan bersedia membayar tinggi kepada kaum selebriti yang disukai dan dihormati oleh khalayak yang menjadi sasaran dan yang diharapkan akan mempengaruhi sikap dan perilaku konsumen yang baik terhadap produk yang didukung.

Dari hasil focus group discussion, hanya ada dua unsur dari kecocokan yang disebutkan oleh responden, yaitu karakter unik etnis endorser dan kedewasaan endorser, namun sasaran sabun mandi Lux bukan menjurus kepada etnis tertentu tapi semua orang, khususnya wanita.

\section{Uraian Analisa Persepsi Konsumen Terhadap Citra Produk Lux}

Dari deskripsi tabel hasil focus group di atas, dapat dianalisa bagaimana konsumen mempersepsi produk Lux. Parameter yang terisi dari hasil fgd di atas yaitu sincerity, excitement, competence, dan sophisticating. Dimensi terbesar yang dipersepsi oleh konsumen merupakan dimensi sincerity dan sophisticating. Sedangkan dimensi excitement dan competence kurang dinilai oleh konsumen.

Sincerity yang disebutkan oleh responden dalam fgd antara lain unsur kecocokan produk, tekstur produk, wangi produk dan harga produk Lux. Total 16 kotak dari 40 kotak terisi. Unsur sincerity yang dipersepsi paling baik oleh responden adalah harga produk Lux, disusul dengan tekstur dan kecocokan responden terhadap produk. Wangi produk dipersepsi paling rendah. Keseluruhan konsumen menganggap harga Lux yang terjangkau merupakan kekuatan dalam dimensi sincerity produk.

Competence dipersepsi kurang oleh responden, hanya ada satu unsur yaitu promosi dan hanya terisi 2 kotak dari 10 kotak yang tersedia. Promosi yang dimaksud adalah promosi iklan Lux berupa hadiah-hadiah yang didapat bersamaan dengan saat pembelian sabun, promosi Lux spa, dan potongan harga. Dimensi competence Lux dinilai masih kurang.

Dimensi sophisticating dipersepsi dengan baik oleh para responden, dengan adanya tujuh unsur yang muncul, yaitu kemasan produk, eksklusifitas produk, citra iklan glamor (mewah), citra iklan ekslusif, citra iklan mahal, citra iklan cantik dan citra iklan feminin. Kemasan produk Lux dipersepsi baik dan menarik oleh responden, eksklusifitas produk juga dipersepsi dengan baik oleh responden, sedangkan iklan diakui responden merupakan daya tarik utama. Persepsi iklan Lux merupakan iklan yang glamor (mewah) paling besar, disusul citra iklan Lux yang feminin.

Persepsi anggota grup mengenai arti cantik bervariasi, dan dalam prosesnya, peneliti menemukan bahwa memang ada kecenderungan kepada nilai cantik tertentu yang memang sudah ada di masyarakat Indonesia. Secara serempak mereka mengakui, bahwa perempuan yang cantik adalah perempuan yang memiliki kriteria fisik yang mereka sebutkan. Kriterianya yaitu bertubuh tinggi, langsing semampai, berkulit putih bersih, memiliki fitur 
wajah yang baik, misal hidung mancung, mata indah, dan cara berbusana yang modis. Hal tersebut disebutkan oleh mayoritas grup, sehingga dari segi fisik, budaya kecantikan yang dikonstruksi oleh media massa ternyata memang terbukti sudah menciptakan konstruksi cantik tersendiri di mata wanita.

Tabel 2. Analisa persepsi konsumen terhadap citra produk Lux

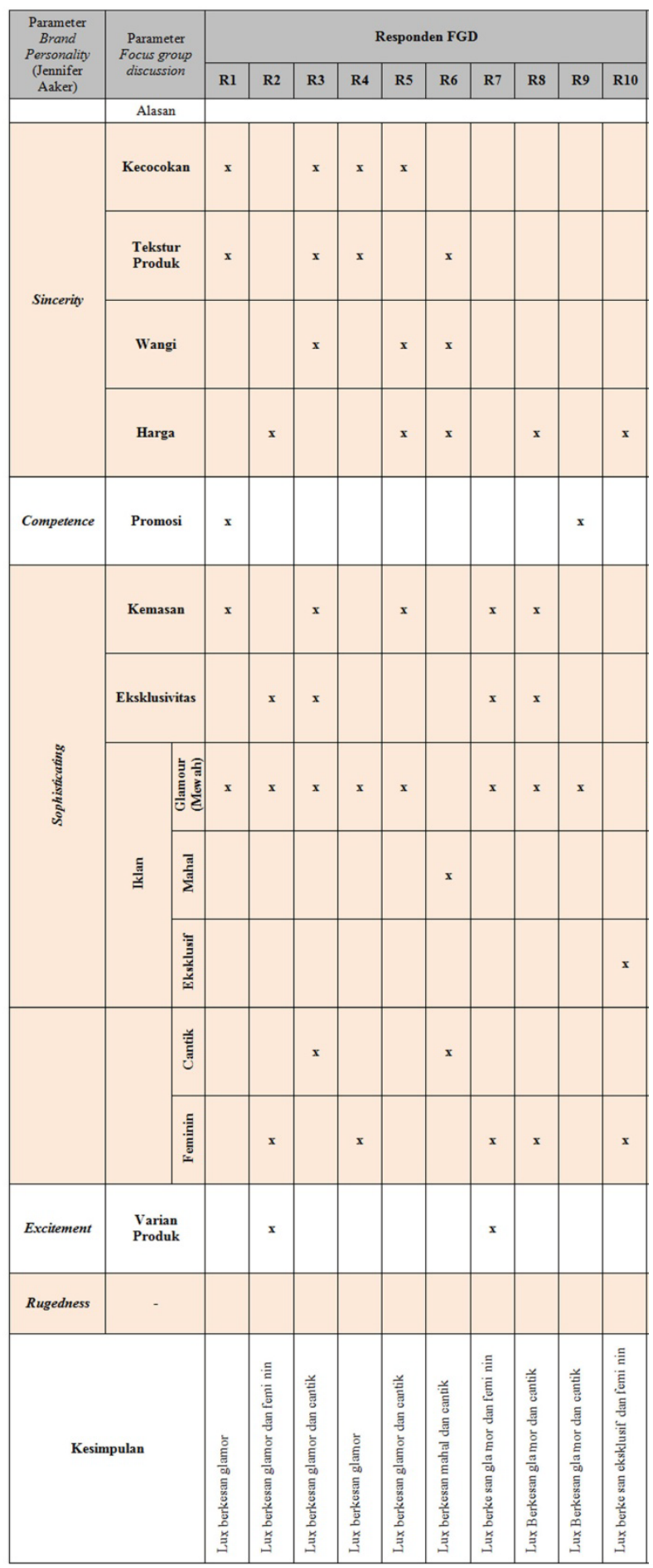

\section{KESIMPULAN}

Endorser merupakan salah satu strategi ampuh yang dapat meningkatkan citra merek di pasaran, dengan beberapa syarat yang memang harus dipenuhi untuk membuat seorang endorser layak atau tidak dalam merepresentasikan suatu produk tertentu. Dibandingkan dengan bintang iklan biasa atau non-selebriti, pasar memang cenderung memberi perhatian lebih kepada produk atau merek yang memasang selebritis sebagai endorsernya [7]. Lux sebagai merek sabun yang merupakan market leader di kelasnya membuktikan hal ini, yaitu secara konsisten menggunakan endorser sebagai juru bicara produk dan alat membentuk image produk.

Konsumen mempersepsi Lux sebagai sebuah merek yang memiliki kepribadian, karena itu Lux dapat bertahan di pasaran dan memiliki basis konsumen yang besar. Lux dipersepsi konsumen antara lain lewat penampilan iklannya yang memberi kesan glamor dan feminin, dan produk yang dipersepsi memiliki kemasan dan harga paling baik. Unsur harga dan kemasan merupakan unsur sophisticating dan sincerity dari sebuah brand personality. Unsur iklan Lux yang dipersepsi dengan sangat baik juga merupakan sophisticating sebuah merek. Konsumen menganggap sabun Lux merupakan merek yang menjual keglamoran dunia selebritis, kemewahan yang diwujudkan dalam bentuk kemasan, namun dengan harga yang terjangkau. Hal tersebut membuktikan bahwa merek merupakan pengalaman dan kesan konsumen terhadap produk, dan bukan merupakan pembentukan image sepihak dari pihak produsen.

Untuk sebuah merek sebesar sabun Lux, segala kriteria pembentuk kepribadian merek sudah terpenuhi, dan persepsi konsumen akan kekuatan kepribadian merek juga sudah terbentuk dengan baik, sehingga apabila keseluruhan unsur pembentuk brand terpenuhi dengan baik, maka loyalitas pelanggan juga akan dicapai. Nilainilai kecantikan yang berkembang di masyarakat merupakan wujud dari budaya kecantikan yang dianut oleh masyarakat, terutama kaum wanitanya. Iklan produk Lux, merupakan salah satu pembentuk nilai-nilai kecantikan yang dianut di masyarakat. Para endorser Lux merupakan cerminan dari stereotip perempuan yang dianggap cantik oleh masyarakat, yaitu perempuan dengan tubuh tinggi, langsing dan kulit putih. Iklan sabun yang merupakan alat pembersih tubuh rupanya juga cerminan stereotip budaya cantik di masyarakat. Stereotip lainnya adalah tubuh yang tinggi dan langsing, fitur wajah yang cenderung kaukasian seperti perwujudan kecantikan para endorser sabun Lux. Konsumen mempersepsi kecantikan dengan penampilan fisik endorser, antara lain Tamara dan Luna. Stereotip tersebut kemudian menjadi standarisasi kecantikan yang timbul dan menjadi patokan masyarakat, perempuan khususnya, dalam memaknai kecantikan fisik. Kecantikan batiniah, di lain pihak memang menjadi perhatian dari kaum perempuan, terlebih perempuan dengan tingkat pendidikan tinggi. Perempuan juga harus memiliki kualitas non-fisik seperti inner beauty, untuk dapat dikatakan cantik, walaupun stereotip kriteria cantik media memang menjadi patokan utama bagi kaum perempuan pada umumnya.

Dari hasil penelitian dan kesimpulan, maka saran yang dihasilkan adalah dalam menggunakan jasa selebriti endorser, memang kriteria daya tarik merupakan hal 
terpenting dalam menjual produk kecantikan kepada konsumen, namun produsen juga harus memperhatikan unsur kredibilitas dan kecocokan dari seorang endorser, agar pesan yang ingin disampaikan kepada konsumen dapat terwujud.

Penelitian tentang persepsi konsumen terhadap citra endorser sekaligus persepsi tentang kecantikan ini merupakan penelitian yang berdasar dari data lapangan tentang image produk sabun Lux yang merupakan market leader di pasar. Strategi beriklan, terlebih iklan yang menjual produk-produk kecantikan akan selalu berubah dan berkembang di setiap masa. Sebuah brand juga akan berkembang terus mengikuti permintaan dan kesukaan pasar, oleh karena ritme periklanan dan budaya kecantikan juga terus berkembang, maka penelitian mengenai branding, ataupun strategi beriklan yang berimbas dengan efek poitif kepada konsumen bisa terus dikembangkan, untuk melihat efektifitas bagaimana sebuah strategi beriklan diterapkan, sekaligus dapat memahami tren pasar yang sedang berkembang.

\section{DAFTAR PUSTAKA}

[1] Widyatama, Rendra. (2005). Pengantar Periklanan. Jakarta: Buana Pustaka Indonesia

[2] Jefkin, Frank. (1997). Periklanan. Jakarta: Penerbit Erlangga.

[3] James F. Engel, Rogers D. Blackwell, Paul W. Miniard. (1994). Perilaku Konsumen. Jakarta: Binarupa Aksara

[4] Berger, A. A. (1982). Media Analysis Techniques. Beverly Hills: Sage Publication

[5] A, Shimp,Terence (2003). Periklanan Promosi \& Aspek Tambahan Komunikasi Pemasaran Terpadu, Jilid I ( edisi 5), Jakarta: Erlangga.

[6] Kotler, Philip. (2003). Manajemen Pemasaran jilid I. Jakarta: Prentice Hall

[7] Priyatna Prabasmoro, Aquarini. (2003). Becoming White: Representasi Ras, Kelas, Feminitas dan Globalitas dalam Iklan Sabun. Yogyakarta: Jalasutra. 